\title{
Mitochondrial Dynamics in Cancer and Neurodegenerative and Neuroinflammatory Diseases
}

\author{
Mauro Corrado, ${ }^{1}$ Luca Scorrano,,${ }^{1,2}$ and Silvia Campello ${ }^{3}$ \\ ${ }^{1}$ University of Geneva, 1211 Geneva, Switzerland \\ ${ }^{2}$ Venetian Institute of Molecular Medicine, 35129 Padova, Italy \\ ${ }^{3}$ IRCCS Fondazione Santa Lucia, 00143 Rome, Italy
}

Correspondence should be addressed to Luca Scorrano, luca.scorrano@unige.ch and Silvia Campello, s.campello@hsantalucia.it

Received 6 March 2012; Accepted 12 April 2012

Academic Editor: Pier Giorgio Mastroberardino

Copyright (C) 2012 Mauro Corrado et al. This is an open access article distributed under the Creative Commons Attribution License, which permits unrestricted use, distribution, and reproduction in any medium, provided the original work is properly cited.

Mitochondria are key organelles in the cell, hosting essential functions, from biosynthetic and metabolic pathways, to oxidative phosphorylation and ATP production, from calcium buffering to red-ox homeostasis and apoptotic signalling pathways. Mitochondria are also dynamic organelles, continuously fusing and dividing, and their localization, size and trafficking are finely regulated. Moreover, in recent decades, alterations in mitochondrial function and dynamics have been implicated in an increasing number of diseases. In this review, we focus on the relationship clarified hitherto between mitochondrial dynamics and cancer, neurodegenerative and neuroinflammatory diseases.

\section{Introduction}

In eukaryotic cells, the role of mitochondria is pivotal both in providing essential molecules and signals for life and in amplifying signals of death. In regard to the cell life, mitochondria produce most of the ATP necessary to the cell through oxidative phosphorylation, and they are involved, among the others, in TCA cycle, fatty acid metabolism, hemesynthesis, and gluconeogenesis. As regards the cell death, mitochondria are involved in $\mathrm{Ca}^{2+}$ and redox homeostasis, which are dysregulated during cell death, and they release proapoptotic proteins, such as cytochrome $c$, SMAC/DIABLO, AIF, Endo G, and Omi/HTRA2, after mitochondrial membrane permeabilization and cristae remodeling $[1-3]$.

Moreover, mitochondria are highly dynamic organelles that can fuse and divide, forming an interconnected network or fragmented units inside the cell, according to different stimuli impinging on the fusion/fission machinery, represented by the mitochondria shaping proteins: MFN1, MFN2, OPA1, regulators of fusion, and DRP1, FIS1, MFF, and MIEF1, which modulate fission [4] (see Figure 1(a)).
1.1. Mitochondrial Fusion. MFN1 and MFN2, two dynaminrelated GTPases, are the main regulators of mitochondrial fusion at the level of outer mitochondrial membrane (OMM). They can interact, forming homo- and heterodimers; after conformational changes led by the hydrolysis of GTP, they force the OMM to fuse [5]. Interestingly, MFN2 is also responsible for $\mathrm{ER} /$ mitochondria tethering with an important implication in $\mathrm{Ca}^{2+}$ homeostasis and signalling [6]. OPA1, another dynamin-related GTPase, is located in the inner mitochondrial membrane (IMM) where, together with MFN1, it plays a role in controlling fusion at this level [7]. OPA1 has also a role in controlling cell-death; in fact, heterocomplexes between proteolytic processed or unprocessed forms of OPA1 regulate the width of cristae junctions and the subsequent release of cytochrome $c$, which then interacts with APAF1 and caspase 9 forming the apoptosome, whose activation results in the amplification of cell death signals $[8,9]$. Other proteins have been linked to mitochondrial fusion, such as LETM1 [10], the Phospholipase D (PLD) [11], and Prohibitins (Phb) [12], the latter necessary for OPA1 processing. 

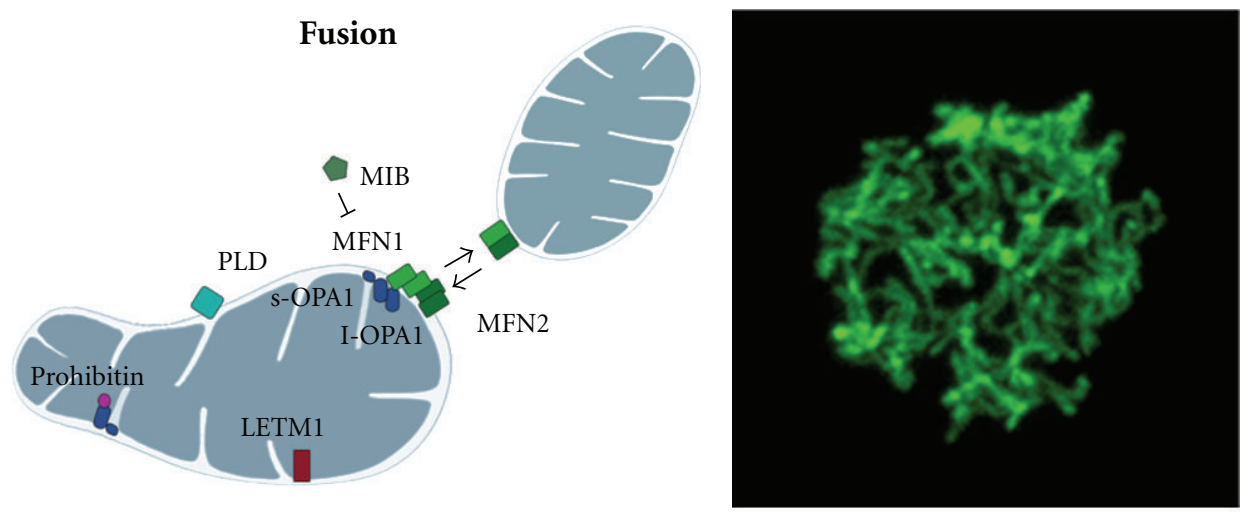

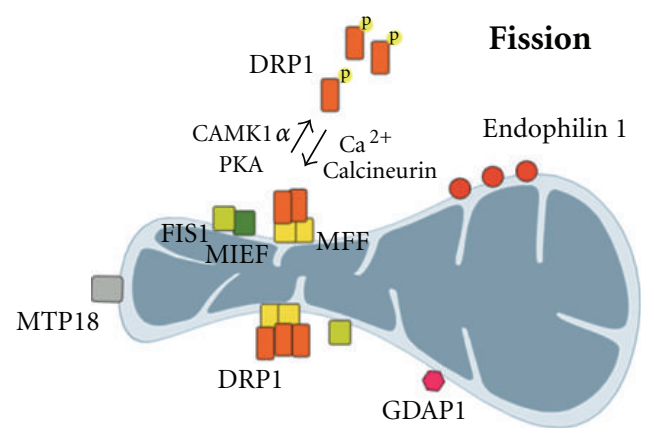

(a)

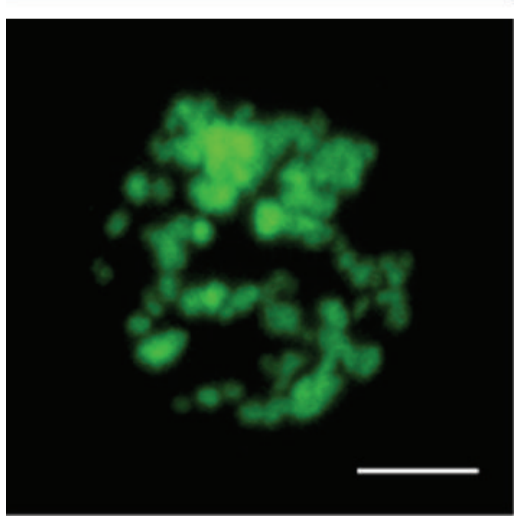

(b)

Figure 1: The dynamic nature of mitochondrial shape. (a) Main proteins involved in mitochondrial shape changes are depicted. In fused unopposed condition, DRP1 is phosphorylated and sequestered in the cytoplasm. Once dephosphorylated, it is recruited to the OMM where it oligomerizes and interacts with FIS1, MFF, or MIEF inducing constriction of membranes and, eventually, fission of mitochondria. MFNs homo- and heterooligomerization on the OMM and oligomerization between long and short isoform of Opal on the IMM control fusion of mitochondrial membranes. Additional proteins affecting mitochondrial shape are also shown. (b) Mitochondrial morphology in Jurkat cells overexpressing yellow fluorescent protein targeted to mitochondria. The upper panel shows a network of elongated and interconnected mitochondria. In the lower panel, mitochondria appear fragmented (Scale bar: $5 \mu \mathrm{m}$ ).

In summary, the pleiotropic mitofusins (MFN1 and MFN2) and OPA1 are the main regulators of the mitochondria fusion machinery. Although steps forward have been made, some points of this mechanism still remain to be clarified; in particular, how the IMM fuses and how its fusion is coordinated with events of the OMM fusion.

1.2. Mitochondrial Fission. The fission machinery is based on DRP1, FIS1, MFF, and MIEF1. DRP1 is a large GTPase protein [13], which in conditions of unopposed fusion is cytosolic and after dephosphorylation by calcineurin is recruited on mitochondria [14], where it oligomerizes and interacts with its putative adaptors on the OMM (FIS1, MFF, and MIEF1), forming ring-shaped structures and inducing mitochondrial constriction and fission [15]. Endophilin B1 [16], MTP18 [17], MIB [18], and GDAP1 [19] have been described, moreover, among the fission components.

The scenario of mitochondrial fission is becoming more complex, taking into account the different roles proposed for MFF, MIEF, and FIS1. MFF has recently been shown to be an adaptor of DRP1 on the OMM [20], whereas the binding of MIEF to DRP1 on the OMM inhibits the GTPase function of DRP1 and its profission activity [21]. On the other hand,
FIS1, that initially was considered the only DRP1 receptor at the OMM, has now been proposed to exert its profission role by interacting and sequestering MIEF, thus allowing DRP1 to mediate the constriction and fission of the membrane [21].

It has also been suggested that mitochondrial fission events predominantly occur at the contact sites between ER and mitochondria, specifically where some ER tubules cross over and wrap around mitochondria. Interestingly, DRP1 and MFF localize at these contact sites [22]. New studies that will address the biochemical mechanism, by which the ER participates in mitochondrial division, placing this observation in the overall picture of mitochondrial division, will be of great interest in the field.

In summary, the fission machinery depends on the activation and translocation of DRP1 to the OMM, where it interacts with some other components, not clearly defined, that take part to the modulation of mitochondrial fragmentation.

\subsection{More than Just Morphology: The Intimate Connection with} Physiological Functions. Changes in mitochondrial morphology have been related to alterations in mitochondrial function, transport, location, and quality control. Mitochondrial 
TABLE 1: Mitochondrial dynamics and cancer.

\begin{tabular}{lccl}
\hline Pathology & $\begin{array}{c}\text { Proteins involved } \\
\text { (expression level) }\end{array}$ & $\begin{array}{c}\text { Mitochondrial } \\
\text { phenotype }\end{array}$ & $\begin{array}{l}\text { Mechanisms of pathophysiology involving } \\
\text { mitochondria }\end{array}$ \\
\hline Different types of tumors & $\begin{array}{c}\text { MFN1, MFN2, OPA1 } \downarrow \downarrow \\
\text { DRP1, FIS1 } \uparrow\end{array}$ & $\begin{array}{l}\text { Inhibition of TCA cycle and oxidative } \\
\text { phosphorylation, mitochondrial membrane } \\
\text { permeabilization; fission accompanied by ROS } \\
\text { production, polarization and chemotaxis of } \\
\text { lymphocytes and tumoral cells [42-45]. }\end{array}$ \\
\hline
\end{tabular}

damage, for example, induces fission, which, in turn, allows mitochondria to be engulfed by the autophagosomes and then degraded [23].

Autophagy represents a cellular self-degradation process involved in the degradation of bulk cytoplasmic components, proteins, or entire organelles in basal or nutrient depleted conditions. This process is also described as macroautophagy and is different from the selective autophagy. The latter is responsible for selective degradation of damaged and dysfunctional organelles, and, thus, it represents the quality control system for mitochondria [23]. In case of damage, mitochondria undergo fragmentation, and PARKIN is recruited to the organelles in a PINK1-dependent manner, allowing their engulfment into the autophagosome and their selective degradation (mitophagy) $[24,25]$. On the other hand, when macroautophagy is induced, mitochondria elongate, being so spared by autophagosomes to ensure the major energy supply required by the cell in starving condition [26]. Besides their role in mitochondrial quality control, PINK1 and PARKIN have also a role in regulating mitochondrial dynamics. Moreover, BNIP3, a BH3-only member of the $\mathrm{Bcl}-2$ family, enlarges the number of proteins crosstalking between autophagy and mitochondrial dynamics [27]. Its misregulation has implications in the development of muscular atrophy [28]. The existence of a crosstalk between autophagy and the mitochondrial dynamics machinery, as well as with the apoptotic process, opens new questions and is in need of further investigations.

To reinforce the idea of an intimate connection between mitochondrial dynamics and function, recently published data have revealed that in vivo genetic ablation of fusion (Opa1 knock-out mice [29, 30], Mfn1/Mfn2 double knockout mice [5]), or fission (Drp1 knock-out mice [31]) proteins results in early embryonic lethality. Other data reveal mutations or abnormal regulation of mitochondria shaping proteins in many pathological conditions, as we will see below.

\section{Cancer}

According to the classification of the hallmarks of cancer by Hanahan and Weinberg [32], a cell needs a multistep process to become tumoral and, later on, to develop metastasis. Mitochondria are crucially positioned for establishing resistance to cell death and sustaining proliferative signallings. Their role is essential for the metabolic shift to glycolysis (the so-called Warburg effect), common in tumoral cells. Increasing evidence shows the involvement of mitochondrial dynamics in cancer development (see Table 1).
2.1. Escaping Cell Death and Regulating Mitochondrial Morphology: A Role for the Bcl-2 Family Proteins. Escaping death signals is one of the first characteristics of a tumoral cell. Bcl2 family proteins play an important role in balancing life and death signals [33] converging on mitochondria and, at the same time, in regulating changes in mitochondrial morphology. Generally, prosurvival signals are associated with elongated mitochondria, while cell death is usually accompanied by mitochondrial fragmentation. BCL-2 is a tumoral marker overexpressed in many lymphomas contributing to resistance to cell death [34-36]. CED-9, the homolog of BCL-2 in C. elegans, is able to interact with MFN2-inducing mitochondrial fusion [37]. BCL- $\mathrm{X}_{\mathrm{L}}$ promotes instead fission stimulating the DRP1 GTPase activity [38]. The proapoptotic BAK and BAX stabilize DRP1 on mitochondria promoting fission [39], indeed, Bak ${ }^{-/-} \mathrm{Bax}^{-/-}$cells have an elongated mitochondrial network [40]. Interestingly, BAX colocalizes with DRP1 and MFN2 at sites of fission so promoting mitochondrial membrane permeabilization [39]. Finally, consistent with their proapoptotic role, NOXA and PUMA trigger DRP1dependent mitochondrial fragmentation [41].

2.2. Metabolic State and Mitochondrial Shape Changes. Another feature of tumoral cells is the already mentioned shift from the production of ATP by oxidative phosphorylation to a glycolytic phenotype despite the presence of oxygen [32]. It is not yet clear if this metabolic modification is an adaptation to a hypoxic microenvironment or the result of defects in OXPHOS respiration. Nevertheless, the existence of a double relationship between mitochondrial morphology and metabolic state is, however, increasingly evident. In OXPHOS cells, mitochondria appear elongated (State III); in glycolytic cells, they have a more fragmented phenotype (state IV) [46, 47]. The molecular mechanism underlying this phenomenon involves fusion proteins: reduced levels of MFN2, MFN1, or OPA1 results in the inhibition of TCA cycle, the decrease of oxidative phosphorylation, and the increase of glycolysis and lactic fermentation [42, 43]. Moreover, in a tumoral mass, the cellular response to hypoxia triggers mitochondrial elongation, dependent on HIF1; this, in turn, increases the resistance to apoptotic stimuli [48]. On the other hand, an efficient oxidative phosphorylation, and the consequent optimal mitochondrial membrane potential, $(\Delta \psi)$, is necessary for mitochondrial fusion $[49,50]$.

2.3. Cell-Cycle Regulation: When Cell Division Means Mitochondrial Fragmentation. It has been shown that mitochondria undergo fragmentation during the $\mathrm{S}$ and $\mathrm{M}$ phase of 
the cell cycle to allow a limitation of the mutation rate during DNA replication, through a temporary decrease of oxidative phosphorylation (which is the main source of ROS). Such fragmentation is also necessary for an equal segregation of mitochondria between the daughter cells [51, 52]. This process is mainly regulated by CDK1/Cyclin B complex, which phosphorylates DRP1 at the beginning of the $S$ phase, resulting in DRP1 recruitment on mitochondria and subsequent mitochondrial fragmentation [53]. Thus, in normal conditions, the fragmentation of mitochondria, required during cell division, is a DRP1- and CDK1dependent process, but in many tumors the cell cycle is dysregulated, and CDK1 activity becomes altered. It remains to be investigated whether this has an effect also on the morphology of mitochondria.

2.4. ROS Production and Mitochondrial Fragmentation. To continue this overview, ROS can be considered as both initiator factors of the tumor (inducing genome and mtDNA mutations) and enhancing factors giving a higher rate of proliferation to the cells $[54,55]$. ROS production is mainly attributed to mitochondria, at the level of respiratory chain, and, in case of mitochondrial fragmentation, it is enhanced. Significantly, ionizing radiation is accompanied by ROS production and mitochondrial fragmentation in a DRP1dependent way, so contributing to genome instability and carcinogenesis [44].

Interestingly, clinical studies of lung adenocarcinoma reveal a role for DRP1, independent of the mitochondrial morphology. In this tumor, DRP1 is overexpressed, but is sequestered in the nucleus by hHR23A, so avoiding its localization on mitochondria and conferring resistance to cisplatin [56]. A central role for mitochondrial dynamics also emerges in other studies. IL- 6 dependent cancer cachexia is characterized by MFNs mRNA reduction and FIS1 mRNA upregulation [57]. FIS1 is also upregulated in some subtypes of human malignant melanoma [58].

In a more general way, cancer cells share characteristics with stem cells, in particular regarding mitochondrial morphology, localization, function, and mtDNA content [59]. Of note, in embryonic stem cells, there is a growth factor erv-1like (GERF)-dependent DRP1 downregulation, which leads to mitochondrial elongation and an enhanced cell viability [60].

Finally, in lymphocytes mitochondria fission and relocalization to the uropod are necessary for the polarization and chemotaxis of these cells [45], so unravelling a possible role for mitochondrial morphology also in metastasis formation, where the acquisition of migratory capability represents the main feature of a metastatic cell phenotype.

\section{Neurodegenerative Diseases}

3.1. Beyond the Morphology: Physiological Mechanisms Affected by Altered Mitochondrial Dynamics in Neurons. Before starting the examination of different pathologies directly related to mitochondrial dynamics failure or imbalance (see Table 2), we would like to give an overview of some of the possible mechanisms whereby mitochondrial dynamics alterations can lead to neurodegeneration: aberrant mitochondrial trafficking, altered interorganellar communication and impaired mitochondrial quality control [61].

3.1.1. Mitochondrial Trafficking. Neurons, especially motor neurons, are characterized by long axons up to more than one meter at the end of which synapses exert their role in cellular-cellular communication. The resulting importance of mitochondrial anterograde transports to the synapses (to ensure ATP production necessary for neurotransmitters vesicles to be discarded [62]) and of retrograde movement to the soma of the cell are both clearly evident. Mitochondria rely on dynein/dynactin motor for the anterograde movement, on kinesin motor for the retrograde one, and on MIRO and MILTON as an additional mitochondrial linker and regulatory proteins [63]. Thus, a defect in the cellular motors, or in the mitochondria compartment to be loaded as cargo, could result in a mitochondrial deficit at synapses and in neurodegeneration. There is no direct correlation described so far in patients although, in some sporadic cases of Alzheimer disease (AD), trafficking alteration has been observed due to mutation in Kinesin1 [64]. That said, increasing data are emerging in experimental models. Anterograde and retrograde trafficking is altered in Amyotrophic lateral sclerosis (ALS) mouse models in which SOD1 $[65,66]$, guanin-nucleotide exchange factor (GEF) and TAR DNA-binding protein 43 (TDP-43) are mutated $[67,68]$. Noteworthy, a role for mitochondrial trafficking impairment has been demonstrated in pathologies not only affecting long axon neurons but also short cortex and hippocampal ones (this is the case of Alzheimer diseaseAD-models) $[64,69,70]$. Similar observations come from works in a Huntington's disease (HD) mouse model, in which mutated $\mathrm{Htt}$ (the gene of HUNTINGTIN protein) is able to block mitochondrial movement [71] and causes a redistribution of kinesin and dynein in primary cortical neurons [72]; in Parkinson disease (PD) cellular and mouse models where PINK1 has been shown to interact with MIRO and MILTON [73], as well as with $\alpha$-SYNUCLEIN, LRRK2, and PARKIN, to disrupt the microtubule network in the cell [74-76].

\subsubsection{Mitochondria-Associated Membranes and $\mathrm{Ca}^{2+}$ Homeo-} stasis. In recent decades, a functional role for mitochondria-ER interactions and $\mathrm{Ca}^{2+}$-signalling implications has emerged [6]. The sites where these two organelles interact are defined as mitochondria-associated membranes (or MAMs), and MFN2 activity is pivotal in ER-mitochondria tethering and MAM formation. MAMs have a role in regulating calcium crosstalk between ER and mitochondria, so avoiding $\mathrm{Ca}^{2+}$ overload in mitochondria in physiological condition and revealing, thus, an unexpected connection with mitochondrial trafficking. In fact, MIRO is a calcium-binding protein; it has been proposed that only in calcium unbound state (low local $\mathrm{Ca}^{2+}$ concentration) is it able to interact with MILTON, so allowing movement of mitochondria [101]. 
TABLe 2: Mitochondrial dynamics and neurodegenerative diseases.

\begin{tabular}{|c|c|c|c|}
\hline Pathology & $\begin{array}{c}\text { Proteins involved } \\
\text { (expression level and/or mutation) }\end{array}$ & $\begin{array}{l}\text { Mitochondrial } \\
\text { phenotype }\end{array}$ & $\begin{array}{l}\text { Mechanisms of pathophysiology } \\
\text { involving mitochondria }\end{array}$ \\
\hline Alzheimer disease & $\begin{array}{l}\text { MFN1, MFN2, OPA } 1 \downarrow \downarrow \\
\text { DRP1, FIS1 } \uparrow \uparrow \\
\text { KINESIN mutation }\end{array}$ & $\begin{array}{l}\text { Fragmentation, } \\
\text { disruption of cristae } \\
\text { structure, reduction in } \\
\text { number of mitochondria } \\
\text { in dendrites, impaired } \\
\text { mitochondrial } \\
\text { trafficking, defects in } \\
\text { KGDH complex, PDH } \\
\text { complex and COX. }\end{array}$ & $\begin{array}{l}\beta \text { amiloyd accumulation and } \\
\text { interaction with DRP1, enhanced } \\
\text { CDK1 activity, altered interaction } \\
\text { between mitochondria and Kinesin } \\
\text { motor complex in cerebral cortex } \\
\text { [77-79]. }\end{array}$ \\
\hline Huntington's disease & $\begin{array}{c}\text { MFN1, MFN2, OPA1 } \downarrow \downarrow \\
\text { DRP1, FIS1 } \uparrow \\
\text { HTT mutation }\end{array}$ & $\begin{array}{l}\text { Fragmentation; } \\
\text { impaired mitochondrial } \\
\text { trafficking, defects in } \\
\text { SDH (complex II) and } \\
\text { Aconitase. }\end{array}$ & $\begin{array}{l}\text { HTT interaction with DRP1, } \\
\text { increased calcineurin and DRP1 } \\
\text { activity, redistribution of kinesin and } \\
\text { dynein motor complexes in striatal } \\
\text { neurons [80-82]. }\end{array}$ \\
\hline Parkinson disease & $\begin{array}{c}\text { Parkin mutation or } \downarrow \downarrow \\
\text { Pink1 mutation or } \downarrow \downarrow \\
\text { DJ-1 mutation } \\
\text { DRP1 } \downarrow \downarrow \\
\text { MFN2 } \\
\alpha \text {-synuclein mutation } \\
\text { LRRK2 mutation } \\
\end{array}$ & $\begin{array}{l}\text { Fragmentation, } \\
\text { impaired mitochondrial } \\
\text { trafficking. }\end{array}$ & $\begin{array}{l}\text { Altered interaction between } \\
\text { mitochondria and motor complexes, } \\
\text { impaired mitophagy of damaged } \\
\text { mitochondria in substantia nigra } \\
{[74,75,83-86] \text {. }}\end{array}$ \\
\hline Amiotrophic lateral sclerosis & $\begin{array}{l}\text { SOD mutation } \\
\text { GEFmutation } \\
\text { TDP-43 mutation }\end{array}$ & $\begin{array}{l}\text { Fragmentation, } \\
\text { disruption of cristae } \\
\text { structure with expansion } \\
\text { of IMS, impaired } \\
\text { mitochondrial } \\
\text { trafficking, complex I } \\
\text { dysfunctions. }\end{array}$ & $\begin{array}{l}\text { Toxicity associated to the formation } \\
\text { of aggregates of mutant SOD, in } \\
\text { subsarcolemmal region of muscles } \\
\text { and anterior horn neurons of lumbar } \\
\text { spinal cord [87-93]. }\end{array}$ \\
\hline $\begin{array}{l}\text { Autosomal dominant optic } \\
\text { atrophy }\end{array}$ & OPA1 mutation & $\begin{array}{l}\text { Fragmentation, complex } \\
\text { I dysfunctions. }\end{array}$ & $\begin{array}{l}\text { Major sensitivity to death stimuli in } \\
\text { retinal ganglion cells and optic nerve } \\
{[94-98] \text {. }}\end{array}$ \\
\hline Charcot Marie Tooth Type 2 & $\begin{array}{l}\text { MFN1 mutation } \\
\text { GDAP1mutation }\end{array}$ & $\begin{array}{l}\text { Fragmentation (MFN1 } \\
\text { mut) or elongation } \\
\text { (GDAP1 mut). }\end{array}$ & $\begin{array}{l}\text { MFN1: probably alteration in } \\
\text { ER-mitocondria tethering and } \\
\text { Calcium signalling [99]; GDAP1: } \\
\text { altered localization of GDAP1 [100]. }\end{array}$ \\
\hline
\end{tabular}

Thus, an alteration in $\mathrm{Ca}^{2+}$ homeostasis, due to abnormal ER-Mito crosstalk, results in impaired mitochondrial movement and consequently in neurodegeneration [101]. Moreover, Amyloid $\beta$, a constituent of extracellular neurite plaques in $\mathrm{AD}$, is abundant in MAMs, contributing to interorganellar dysfunctions [102]. Altered MAM organization has been proposed also for spinocerebellar ataxias (SCA), due to mutation in the regulatory subunit of Protein phosphatase 2A, PPPR2B [103], and for PD, due to mutation in the subunit $2 \mathrm{~b}$ of phospholipase A2 (iPLAS2b). The latter is important in ER-mitochondria crosstalk during apoptosis mediated by ER stress [104].

3.1.3. Mitochondrial Quality Control. The role of mitochondrial quality control is becoming increasingly prominent in the explanation of neurodegenerative diseases such as Parkinson disease (PD) and others. A general mechanism of mitochondrial quality control relies on the PINK1/PARKIN pathway, deeply studied in vitro. Briefly, loss of $\Delta \psi$ induces stabilization of PINK1 on the OMM and allows PARKIN recruitment on mitochondria. This, in turn, leads to ubiquitination of mitochondrial substrates and their interaction with p62 and LC3 so as to induce the engulfment of mitochondria inside the autophagosome [24, 25]. MFNs, for example, are ubiquitinated in a PARKIN-dependent manner [105] and then degraded by proteasome [106]. Others showed that DRP1 stability is also regulated by PARKIN [107].

3.2. Focus on the Pathologies. Coming back to the pathologies, in this paragraph, we will focus on the links between some of them and the mitochondrial dynamics.

3.2.1. Alzheimer Disease. The main clinical feature of Alzheimer disease (AD) is the accumulation of extracellular 
deposits of amyloid $\beta(\mathrm{A} \beta)$ plaques and tau-containing intracellular neurofibrillary tangles in the brain, these leading to progressive neuronal death. From a morphological point of view, neurons expressing amyloid protein precursor (APP), or Amyloid $\beta$, show abnormal levels of mitochondrial shaping proteins with downregulation of MFNs and OPA1 and upregulation of DRP1 and FIS1 [69, 70, 108, 109]. Amyloid $\beta$ interacts with DRP1 [77], promoting mitochondrial fission in a DRP1 S-nitrosilation-dependent manner $[110,111]$. Tissues from patients affected by $\mathrm{AD}$ show mitochondria with disrupted cristae structure [112] and reduction of the number of mitochondria in dendrites [69]. Interestingly, although cell-cycle-coupled events are rare in postmitotic cells, the activity of CDK1 and CDK5 is enhanced in AD. CDK5 phosphorylates tau [78], while a high level of phosphorylated DRP1 at Serine 616 appears to be dependent on both CDK1 and protein kinase C $\delta(\mathrm{PKC} \delta)$ [79], as it has been shown in rat primary neurons.

3.2.2. Huntington's Disease. A mitochondrial connection is emerging also in Huntington's disease (HD); mitochondrial succinate dehydrogenase (SDH, complex II), aconitase defects [80], and mtDNA damage [113] have been reported in in vivo models of HD. In addition, 3-nitropropionic acid, an irreversible inhibitor of complex II, has been shown to induce mitochondrial fragmentation and HD-like symptoms in rats and mice [81]. Of note is that primary striatal neurons from HD mouse models reveal mitochondrial fragmentation [114] with an alteration of mitochondrial shaping proteins in the brain (DRP1 and FIS1 upregulation, OPA1 and MFN1 downregulation) [115]. Mutant HUNTINGTIN is able to bind DRP1, increasing its GTPase activity and inducing mitochondria fragmentation both in mice and in human brains [82]. This phenotype is rescued by MFNs or DRP1K38A-dominant negative overexpression and by the use of two DRP1 inhibitors, mdivil or miR-499 [116-120].

3.2.3. Parkinson Disease. Independent studies identified $\alpha$ synuclein, Pink1, Parkin, DJ-1, and Leucine-rich repeat kinase 2 (LRRK2) as commonly mutated genes in Parkinsonism. $\alpha$ SYNUCLEIN and LRRK2 have been proposed as playing a role in microtubule organization and, thus, in mitochondrial trafficking $[74,75]$. PINK1 and PARKIN are key proteins in mitochondrial quality control $[24,25]$, as we discussed above. Interestingly, opposite to what has been observed in drosophila [121, 122], downregulation of PINK1 or PARKIN by siRNA in neuroblastoma cells leads to mitochondrial fragmentation [83]. Also in this case, this fragmentation is rescued by genetically forcing the mitochondria morphology equilibrium towards fusion, or by treatment with the calcineurin inhibitor FK506 [84, 85]. The recruitment of PARKIN to mitochondria has been nicely investigated in different models; generally, it has been shown that upon mitochondrial membrane depolarization PARKIN is recruited to mitochondria both in primary and cultured cell models [25], but this mechanism is also inhibited in primary neurons [86]. The apparent discrepancy in the results among different experimental models could be explained, at least in part, by the observation that those cell models rely on different bioenergetic systems. It has been shown, in fact, that, in primary rat neurons, which largely depend on mitochondrial respiration to produce ATP, or in nonneuronal cells forced to mitochondrial respiration, PARKIN fails to translocate to mitochondria after membrane depolarization in contrast to what is observed in cells relying on glycolytic production of ATP [86]. This suggests that additional regulatory and/or protective mechanisms against mitochondrial damage have to be investigated in neurons. We should also consider that, in all these studies, loss of $\Delta \psi$ is obtained by treating cells with high concentrations (or for long terms) of the protonophores CCCP or FCCP. A common challenge in the next future will be the identification and the use of more physiological stimuli to induce mitochondrial damage, and mitophagy, to better mimic the in vivo mechanism of pathophysiology of neurodegenerative diseases. By this way, it will be possible to clarify some of the discrepancies remaining in the field such as, for example, the differences observed so far for the PINK1/PARKIN functional interaction in various cell lines; or considering the loss of $\Delta \psi$ (artificially induced and forced in all the in vitro experiments performed until now) as the only event triggering mitophagy, another point highly debated and controversial to date.

A mouse model of DJ-1 knockout presents mitochondrial fragmentation [123], increased ROS production, and reduced respiration rates accompanied by basal autophagy impairment [124]. Complex I dysfunctions are common in $\mathrm{PD}$, and its inhibition, by rotenone or 6-hydroxydopamine (6-OHDA) treatment, results in a DRP1-dependent mitochondrial fragmentation in neurons $[125,126]$, so suggesting another link between bioenergetic dysfunctions and altered mitochondrial dynamics in neurodegenerative diseases.

3.2.4. Amyotrophic Lateral Sclerosis. In the $20 \%$ of patients affected by an autosomal dominant form of amyotrophic lateral sclerosis (ALS), a gain of function mutation in SOD1 has been detected [87]. Defects of complex IV activity and mtDNA rearrangement have been also reported in patients affected by ALS [127, 128]. Abnormal aggregation of mitochondria is common in the subsarcolemmal region of muscles and in the anterior horn neurons of the lumbar spinal cord $[88,89]$. At ultrastructural levels, in the case of ALS, mitochondria show disorganized cristae with expansion of intermembrane space (IMS) [90, 91]. Of note, the overexpression of a mutated form of SOD1 in ALS (SOD1G93A) induces fragmentation of mitochondria in NSC-34 motoneuronal-like cells [92]. Moreover, motor neurons from mice overexpressing SOD1-G93A show impaired mitochondrial fusion both in axons and in the cell body with impaired retrograde axonal transport and reduction of frequency and speed of the movement [93].

3.2.5. Autosomal Dominant Optic Atrophy. Opa1 mutations are responsible for the autosomal dominant optic atrophy (ADOA) $[94,95]$. Contrary effects regarding oxidative phosphorylation impairment related to this disease have been published. Phosphorus magnetic resonance spectroscopy 
and luciferin/luciferase assays of muscle cells from ADOA patients showed a reduced ATP production mainly due to reduced complex I activity $[129,130]$. On the other hand, in other studies, no energetic impairment was observed in lymphoblasts and muscle cells from ADOA patients $[96,97]$. Whatever the case, consistent with the role of OPA1 in regulating mitochondrial dynamics, mitochondrial fragmentation is a common feature of ADOA with a severity score of the pathology directly proportional to the level of fragmentation observed [97, 98, 130]. Interestingly, fibroblasts from ADOA patients also reveal a major sensitivity to death stimuli [98], in line with the antiapoptotic role of OPA1 described above [8].

\subsubsection{Other Neuropathies and Neurological Disorders.} Among other neuropathies Leber hereditary optic neuropathy (LHON) has, as a primary cause, mutations in mtDNA [131]. Recently, a possible link with mitochondrial dynamics has been presented in a genome-wide linkage scan study, in which a mutation in Parl (the mitochondrial protease responsible for OPA1 cleavage, [132]) has been associated with LHON [133].

MFN2 is involved in the most common form of the autosomal dominant axonal Charcot-Marie-Tooth (CMT2A) disease [99]. Moreover, ganglioside-induced differentiationassociated protein 1 (GDAP1), whose mutations cause an autosomal recessive form of CMT, appears to be related to mitochondrial fission in mammalian cells [100].

In addition, in a mouse model of apoptosis-inducing factor (AIF) deficiency, MFN1 levels are decreased in the cerebellum and are accompanied by death of Purkinije cells [134]. This phenomenon is generally observed in many neurological diseases such as autism, $\mathrm{HD}, \mathrm{AD}$, multiple system atrophy, and epilepsy [135]. Consistently, also in $M f n 2$ knock-out systems, death of Purkinije cells has been observed, confirming a role for MFNs in protecting against lack of mtDNA and dysfunction of mitochondria in the cerebellum [136].

In the last decade, a link between neurological and lymphatic aspects has emerged in schizophrenia [137]. Recently, a study in schizophrenia-derived lymphoblastoids revealed altered oxidative phosphorylation at level of complex I and clustering of mitochondria in a limited area of the cell, with a reduction in OPA1 expression levels [138].

To conclude, neurons rely on mitochondrial distribution, function, and dynamics to allow synapses and dendrites formation, energy supply, and quality control. The main properties of neurons constitute risk factors themselves if we consider the effects of mitochondrial dysfunctions. First, they are cells highly demanded in energy; second, they have long processes connecting the soma to synapses and dendritic spines; third, they are long-lived postmitotic cells. Although knowledge is increasing about mitochondrial role in neurodegenerative diseases, much remains to be elucidated, in particular, why different subpopulations of neurons are more vulnerable to mitochondrial fusion/fission imbalance and dysfunctions.

\section{Neuroinflammatory and Autoimmune Diseases}

Little is known about the link between mitochondrial dynamics and neuroinflammatory or autoimmune diseases. In this section we present correlations described to date with multiple sclerosis (MS) and type I diabetes, as examples for this category of diseases (see Table 3 ). We then introduce some general outcomes about mitochondrial dynamics and T-cell compartment with the potential for opening up new perspectives regarding cellular mechanisms and clinical therapies for many pathologies.

4.1. Optic Neuritis and Multiple Sclerosis. Optic neuritis $(\mathrm{ON})$ is a neuropathy characterized by demyelination of the optic nerve; it can be present by itself or as part of MS. Multiple sclerosis is an autoimmune disorder characterized by chronic demyelination of the central nervous system (CNS). The pathogenesis of MS is thought to involve selfantigen-reactive $\mathrm{T}$ lymphocytes that have the capacity to invade the CNS and to promote tissue damage.

It is not rare to find mtDNA mutations and mitochondrial abnormalities in patients affected by ON [143]. For instance, in a case of OPA1 mutation (S646L) ADOA has been shown to be associated with MS. This mutation leads to reduction of respiratory rates with lower ATP production [139], which is implicated in demyelination of axons in MS [140]. Interestingly, it has been shown that symptoms of autoimmune disorders, including MS, improve during pregnancy due, at least in part, to the expression of embryoderived preimplantation factor (PIF). This protein is able to reduce neuroinflammation and to promote neural repair in the experimental autoimmune encephalomyelitis (EAE) model of MS, through a general decrease in proinflammatory cytokine and chemokine secretion, and a downregulation of proapoptotic factors and of activating and migrating proteins such as OPA1 [144].

4.2. Type I Diabetes. Type I diabetes is an autoimmune disorder caused by autoimmune elimination of insulin-producing $\beta$ cells in the pancreas, clinically leading to increased glucose in blood and urine. Coronary endothelial cells from diabetic mice are characterized by fragmented mitochondria with a downregulation of OPA1 and an upregulation of DRP1 [141]. In addition, Prohibitin (Phb) has been shown to have a protective role in $\beta$ cells [142]. Interestingly, phb-genetic ablation results in aberrant mitochondrial cristae structure and an increased apoptosis, dependent on increased proteolytic processing of OPA1 [15]. Moreover, it has been shown that the embryo-derived preimplantation factor (PIF) also prevents type I diabetes in mouse models of this disease [145].

4.3. Mitochondrial Morphology and T-Cell Function. The importance of mitochondrial localization and activity in $\mathrm{T}$ cell function is well established. T cells are activated at the so-called "immunological synapse" between a T cell and an antigen-presenting cell (APC) [146]. Mitochondria usually 
TABLE 3: Mitochondrial dynamics and neuroinflammatory and autoimmune diseases.

\begin{tabular}{lcll}
\hline Pathology & $\begin{array}{c}\text { Proteins involved } \\
\text { (expression level and/or mutation) }\end{array}$ & $\begin{array}{l}\text { Mitochondrial } \\
\text { phenotype }\end{array}$ & $\begin{array}{l}\text { Mechanisms of pathophysiology } \\
\text { involving mitochondria }\end{array}$ \\
\hline Multiple sclerosis & OPA1 mutation & Fragmentation. & $\begin{array}{l}\text { Reduction of respiratory rates with lower } \\
\text { ATP production [139, 140]. }\end{array}$ \\
\hline Type 1 diabetes & OPA1 $\downarrow \downarrow$ & $\begin{array}{l}\text { Fragmentation, } \\
\text { disruption of cristae } \\
\text { structure. }\end{array}$ & $\begin{array}{l}\text { Alteration in OPA1 processing in } \beta \text {-cells } \\
\text { in the pancreas and coronary endothelial } \\
\text { cells from diabetic animals [141, 142]. }\end{array}$ \\
\hline
\end{tabular}

fragment and relocalize at the immunological synapse in close proximity to the plasma membrane to buffer $\mathrm{Ca}^{2+}$ entrance and to avoid calcium-dependent T-cell inactivation [147]. Moreover, upon activation, T cells migrate to the site of inflammation towards a chemoattractant gradient. Our group reported that mitochondria allow lymphocyte migration by relocating and accumulating at the uropod (the posterior area of an activated $\mathrm{T}$ cell) where they can provide the necessary energy to class II myosin proteins, these being the major cellular motors. Interestingly, this reorganization needs mitochondrial fission while a forced fusion inhibits both mitochondrial relocalization and lymphocyte migration [45]. In recent years, the polarization of mitochondria towards cell-cell surface has also been shown to occur between natural killer (NK) and tumoral cells [148, 149].

Mitochondrial fission, driven by FIS1 and DRP1, also contributes to the immune system tolerance and the tumorimmune escape in a galectin-1 (GAL-1)-dependent manner. GAL-1 sensitizes resting and activated $\mathrm{T}$ cells to FASmediated cell death program, which is characterized by mitochondrial dysfunctions, membrane potential alteration, mitochondrial fission, and cytochrome $c$ release [150].

It still remains to be elucidated whether or not mitochondrial dynamics play a crucial role in other important physiological processes in $\mathrm{T}$ cells.

Finally, CD47 can trigger cell death in a B lymphocyte leukemia. Also this apoptotic pathway is characterized by DRP1 translocation to mitochondria, which depends on chymotrypsin-like proteases, $\Delta \psi$ loss and ROS production [151]. This last observation is an indication of a possible role of mitochondrial dynamics in general in the whole immune system, more than only in the T-cell physiology and pathophysiology.

\section{Conclusion}

The observations here presented suggest a prominent role for mitochondrial dynamics in a plethora of pathways from cell proliferation to resistance to apoptosis, from cellenergetic requirements to quality control mechanisms, from homeostasis to activation and movement of immune system cells. However our observations also suggest the potential for many new findings to come. The aim of future studies would, therefore, be to extend our knowledge of basic mechanisms underlying pathologies, and their relationship with mitochondrial morphology alterations. This, in turn, could make it possible to draw up novel strategies and treatments to improve the prognosis of an increasing number of patients.

\section{Acknowledgments}

S. Campello is presently funded by the Italian Ministry of Health (GR program) and the AIRC program MyFAG; L. Scorrano is a senior Telethon scientist of the Dulbeccotelethon Institute and is supported by Swiss national Foundation Grant 31-118171, oncoSuisse and Telethon Italy.

\section{References}

[1] L. Ernster and G. Schatz, "Mitochondria: a historical review," Journal of Cell Biology, vol. 91, no. 3, pp. 227-255, 1981.

[2] R. Rizzuto, P. Bernardi, and T. Pozzan, "Mitochondria as allround players of the calcium game," Journal of Physiology, vol. 529, no. 1, pp. 37-47, 2000.

[3] L. Scorrano, "Opening the doors to cytochrome c: changes in mitochondrial shape and apoptosis," International Journal of Biochemistry and Cell Biology, vol. 41, no. 10, pp. 1875-1883, 2009.

[4] J. Bereiter-Hahn and M. Voth, "Dynamics of mitochondria in living cells: shape changes, dislocations, fusion, and fission of mitochondria," Microscopy Research and Technique, vol. 27, no. 3, pp. 198-219, 1994.

[5] H. Chen, S. A. Detmer, A. J. Ewald, E. E. Griffin, S. E. Fraser, and D. C. Chan, "Mitofusins Mfn1 and Mfn2 coordinately regulate mitochondrial fusion and are essential for embryonic development," Journal of Cell Biology, vol. 160, no. 2, pp. 189-200, 2003.

[6] O. M. De Brito and L. Scorrano, "Mitofusin 2 tethers endoplasmic reticulum to mitochondria," Nature, vol. 456, no. 7222, pp. 605-610, 2008.

[7] S. Cipolat, O. M. de Brito, B. Dal Zilio, and L. Scorrano, "OPA1 requires mitofusin 1 to promote mitochondrial fusion," Proceedings of the National Academy of Sciences of the United States of America, vol. 101, no. 45, pp. 15927-15932, 2004.

[8] C. Frezza, S. Cipolat, O. Martins de Brito et al., "OPA1 Controls Apoptotic Cristae Remodeling Independently from Mitochondrial Fusion,” Cell, vol. 126, no. 1, pp. 177-189, 2006.

[9] N. Ishihara, Y. Fujita, T. Oka, and K. Mihara, "Regulation of mitochondrial morphology through proteolytic cleavage of OPA1," The EMBO Journal, vol. 25, no. 13, pp. 2966-2977, 2006.

[10] K. S. Dimmer, F. Navoni, A. Casarin et al., "LETM1, deleted in Wolf-Hirschhorn syndrome is required for normal 
mitochondrial morphology and cellular viability," Human Molecular Genetics, vol. 17, no. 2, pp. 201-214, 2008.

[11] S. Y. Choi, P. Huang, G. M. Jenkins, D. C. Chan, J. Schiller, and M. A. Frohman, "A common lipid links Mfn-mediated mitochondrial fusion and SNARE-regulated exocytosis," Nature Cell Biology, vol. 8, no. 11, pp. 1255-1262, 2006.

[12] C. Merkwirth, S. Dargazanli, T. Tatsuta et al., "Prohibitins control cell proliferation and apoptosis by regulating OPA1dependent cristae morphogenesis in mitochondria," Genes and Development, vol. 22, no. 4, pp. 476-488, 2008.

[13] E. Smirnova, L. Griparic, D. L. Shurland, and A. M. Van der Bliek, "Dynamin-related protein Drp1 is required for mitochondrial division in mammalian cells," Molecular Biology of the Cell, vol. 12, no. 8, pp. 2245-2256, 2001.

[14] G. M. Cereghetti, A. Stangherlin, O. Martins De Brito et al., "Dephosphorylation by calcineurin regulates translocation of Drp1 to mitochondria," Proceedings of the National Academy of Sciences of the United States of America, vol. 105, no. 41, pp. 15803-15808, 2008.

[15] J. A. Mears, L. L. Lackner, S. Fang, E. Ingerman, J. Nunnari, and J. E. Hinshaw, "Conformational changes in Dnm1 support a contractile mechanism for mitochondrial fission," Nature Structural and Molecular Biology, vol. 18, no. 1, pp. 20-26, 2011.

[16] M. Karbowski, S. Y. Jeong, and R. J. Youle, "Endophilin B1 is required for the maintenance of mitochondrial morphology," Journal of Cell Biology, vol. 166, no. 7, pp. 1027-1039, 2004.

[17] D. Tondera, F. Czauderna, K. Paulick, R. Schwarzer, J. Kaufmann, and A. Santel, "The mitochondrial protein MTP18 contributes to mitochondrial fission in mammalian cells," Journal of Cell Science, vol. 118, no. 14, pp. 3049-3059, 2005.

[18] Y. Eura, N. Ishihara, T. Oka, and K. Mihara, "Identification of a novel protein that regulates mitochondrial fusion by modulating mitofusin (Mfn) protein function," Journal of Cell Science, vol. 119, no. 23, pp. 4913-4925, 2006.

[19] L. Pedrola, A. Espert, X. Wu, R. Claramunt, M. E. Shy, and F. Palau, "GDAP1, the protein causing Charcot-Marie-Tooth disease type 4A, is expressed in neurons and is associated with mitochondria," Human Molecular Genetics, vol. 14, no. 8, pp. 1087-1094, 2005.

[20] H. Otera, C. Wang, M. M. Cleland et al., "Mff is an essential factor for mitochondrial recruitment of Drp1 during mitochondrial fission in mammalian cells," Journal of Cell Biology, vol. 191, no. 6, pp. 1141-1158, 2010.

[21] J. Zhao, T. Liu, S. Jin et al., "Human MIEF1 recruits Drp1 to mitochondrial outer membranes and promotes mitochondrial fusion rather than fission," The EMBO Journal, vol. 30, no. 14, pp. 2762-2778, 2011.

[22] J. R. Friedman, L. L. Lackner, M. West, J. R. DiBenedetto, J. Nunnari, and G. K. Voeltz, "ER tubules mark sites of mitochondrial division," Science, vol. 334, no. 6054, pp. 358362, 2011.

[23] R. J. Youle and D. P. Narendra, "Mechanisms of mitophagy," Nature Reviews Molecular Cell Biology, vol. 12, no. 1, pp. 914, 2011.

[24] D. P. Narendra, S. M. Jin, A. Tanaka et al., "PINK1 is selectively stabilized on impaired mitochondria to activate Parkin," PLoS Biology, vol. 8, no. 1, Article ID e1000298, 2010.

[25] D. Narendra, A. Tanaka, D. F. Suen, and R. J. Youle, "Parkin is recruited selectively to impaired mitochondria and promotes their autophagy," Journal of Cell Biology, vol. 183, no. 5, pp. 795-803, 2008.
[26] L. C. Gomes, G. D. Benedetto, and L. Scorrano, "During autophagy mitochondria elongate, are spared from degradation and sustain cell viability," Nature Cell Biology, vol. 13, no. 5, pp. 589-598, 2011.

[27] T. Landes, L. J. Emorine, D. Courilleau, M. Rojo, P. Belenguer, and L. Arnauné-Pelloquin, "The BH3-only Bnip3 binds to the dynamin Opal to promote mitochondrial fragmentation and apoptosis by distinct mechanisms," EMBO Reports, vol. 11, no. 6, pp. 459-465, 2010.

[28] V. Romanello, E. Guadagnin, L. Gomes et al., "Mitochondrial fission and remodelling contributes to muscle atrophy," The EMBO Journal, vol. 29, no. 10, pp. 1774-1785, 2010.

[29] M. V. Alavi, S. Bette, S. Schimpf et al., "A splice site mutation in the murine Opal gene features pathology of autosomal dominant optic atrophy," Brain, vol. 130, no. 4, pp. 10291042, 2007.

[30] V. J. Davies, A. J. Hollins, M. J. Piechota et al., "Opa1 deficiency in a mouse model of autosomal dominant optic atrophy impairs mitochondrial morphology, optic nerve structure and visual function," Human Molecular Genetics, vol. 16, no. 11, pp. 1307-1318, 2007.

[31] N. Ishihara, M. Nomura, A. Jofuku et al., "Mitochondrial fission factor Drp1 is essential for embryonic development and synapse formation in mice," Nature Cell Biology, vol. 11, no. 8, pp. 958-966, 2009.

[32] D. Hanahan and R. A. Weinberg, "Hallmarks of cancer: the next generation," Cell, vol. 144, no. 5, pp. 646-674, 2011.

[33] B. Levine, S. Sinha, and G. Kroemer, "Bcl-2 family members: dual regulators of apoptosis and autophagy," Autophagy, vol. 4, no. 5, pp. 600-606, 2008.

[34] Y. Tsujimoto, L. R. Finger, and J. Yunis, "Cloning of the chromosome breakpoint of neoplastic B cells with the $\mathrm{t}(14 ; 18)$ chromosome translocation," Science, vol. 226, no. 4678, pp. 1097-1099, 1984.

[35] A. Bakhshi, J. P. Jensen, and P. Goldman, "Cloning the chromosomal breakpoint of $\mathrm{t}(14 ; 18)$ human lymphomas: clustering around $\mathrm{J}(\mathrm{H})$ on chromosome 14 and near a transcriptional unit on 18," Cell, vol. 41, no. 3, pp. 899-906, 1985.

[36] M. Crescenzi, M. Seto, G. P. Herzig, P. D. Weiss, R. C. Griffith, and S. J. Korsmeyer, "Thermostable DNA polymerase chain amplification of $\mathrm{t}(14 ; 18)$ chromosome breakpoints and detection of minimal residual disease," Proceedings of the National Academy of Sciences of the United States of America, vol. 85, no. 13, pp. 4869-4873, 1988.

[37] P. Delivani, C. Adrain, R. C. Taylor, P. J. Duriez, and S. J. Martin, "Role for CED-9 and Egl-1 as regulators of mitochondrial fission and fusion dynamics," Molecular Cell, vol. 21, no. 6, pp. 761-773, 2006.

[38] H. Li, Y. Chen, A. F. Jones et al., "Bcl-xL induces Drp1dependent synapse formation in cultured hippocampal neurons," Proceedings of the National Academy of Sciences of the United States of America, vol. 105, no. 6, pp. 2169-2174, 2008.

[39] S. Wasiak, R. Zunino, and H. M. McBride, "Bax/Bak promote sumoylation of DRP1 and its stable association with mitochondria during apoptotic cell death," Journal of Cell Biology, vol. 177, no. 3, pp. 439-450, 2007.

[40] M. Karbowski, K. L. Norris, M. M. Cleland, S. Y. Jeong, and R. J. Youle, "Role of Bax and Bak in mitochondrial morphogenesis," Nature, vol. 443, no. 7112, pp. 658-662, 2006.

[41] J. X. Wang, Q. Li, and P. F. Li, "Apoptosis repressor with caspase recruitment domain contributes to chemotherapy 
resistance by abolishing mitochondrial fission mediated by dynamin-related protein-1," Cancer Research, vol. 69, no. 2, pp. 492-500, 2009.

[42] H. Chen, A. Chomyn, and D. C. Chan, "Disruption of fusion results in mitochondrial heterogeneity and dysfunction," The Journal of Biological Chemistry, vol. 280, no. 28, pp. 26185-26192, 2005.

[43] S. Pich, D. Bach, P. Briones et al., "The Charcot-Marie-Tooth type $2 \mathrm{~A}$ gene product, Mfn2, up-regulates fuel oxidation through expression of OXPHOS system," Human Molecular Genetics, vol. 14, no. 11, pp. 1405-1415, 2005.

[44] S. Kobashigawa, K. Suzuki, and S. Yamashita, "Ionizing radiation accelerates Drp1-dependent mitochondrial fission, which involves delayed mitochondrial reactive oxygen species production in normal human fibroblast-like cells," Biochemical and Biophysical Research Communications, vol. 414, no. 4, pp. 795-800, 2011.

[45] S. Campello, R. A. Lacalle, M. Bettella, S. Mañes, L. Scorrano, and A. Viola, "Orchestration of lymphocyte chemotaxis by mitochondrial dynamics," Journal of Experimental Medicine, vol. 203, no. 13, pp. 2879-2886, 2006.

[46] C. R. Hackenbrock, "Ultrastructural bases for metabolically linked mechanical activity in mitochondria. I. Reversible ultrastructural changes with change in metabolic steady state in isolated liver mitochondria," Journal of Cell Biology, vol. 30, no. 2, pp. 269-297, 1966.

[47] C. R. Hackenbrock, "Energy-linked ultrastructural transformations in isolated liver mitochondria and mitoplasts. Preservation of configurations by freeze-cleaving compared to chemical fixation," Journal of Cell Biology, vol. 53, no. 2, pp. 450-465, 1972.

[48] J. Chiche, M. Rouleau, P. Gounon, M. C. Brahimi-Horn, J. Pouysségur, and N. M. Mazure, "Hypoxic enlarged mitochondria protect cancer cells from apoptotic stimuli," Journal of Cellular Physiology, vol. 222, no. 3, pp. 648-657, 2010.

[49] F. Legros, A. Lombès, P. Frachon, and M. Rojo, "Mitochondrial fusion in human cells is efficient, requires the inner membrane potential, and is mediated by mitofusins," Molecular Biology of the Cell, vol. 13, no. 12, pp. 4343-4354, 2002.

[50] G. Bernard, N. Bellance, D. James et al., "Mitochondrial bioenergetics and structural network organization," Journal of Cell Science, vol. 120, no. 5, pp. 838-848, 2007.

[51] S. Barni, L. Sciola, A. Spano, and P. Pippia, "Static cytofluorometry and fluorescence morphology of mitochondria and DNA in proliferating fibroblasts," Biotechnic and Histochemistry, vol. 71, no. 2, pp. 66-70, 1996.

[52] D. H. Margineantu, W. Gregory Cox, L. Sundell, S. W. Sherwood, J. M. Beechem, and R. A. Capaldi, "Cell cycle dependent morphology changes and associated mitochondrial DNA redistribution in mitochondria of human cell lines," Mitochondrion, vol. 1, no. 5, pp. 425-435, 2002.

[53] N. Taguchi, N. Ishihara, A. Jofuku, T. Oka, and K. Mihara, "Mitotic phosphorylation of dynamin-related GTPase Drp1 participates in mitochondrial fission," The Journal of Biological Chemistry, vol. 282, no. 15, pp. 11521-11529, 2007.

[54] L. Behrend, G. Henderson, and R. M. Zwacka, "Reactive oxygen species in oncogenic transformation," Biochemical Society Transactions, vol. 31, no. 6, pp. 1441-1444, 2003.

[55] D. C. Wallace, "A mitochondrial paradigm of metabolic and degenerative diseases, aging, and cancer: a dawn for evolutionary medicine," Annual Review of Genetics, vol. 39, pp. 359-407, 2005.
[56] Y. Y. Chiang, S. L. Chen, Y. T. Hsiao et al., "Nuclear expression of dynamin-related protein 1 in lung adenocarcinomas," Modern Pathology, vol. 22, no. 9, pp. 1139-1150, 2009.

[57] J. P. White, K. A. Baltgalvis, M. J. Puppa, S. Sato, J. W. Baynes, and J. A. Carson, "Muscle oxidative capacity during IL-6dependent cancer cachexia," American Journal of Physiology, vol. 300, no. 2, pp. R201-R211, 2011.

[58] D. M. Su, Q. Zhang, X. Wang et al., "Two types of human malignant melanoma cell lines revealed by expression patterns of mitochondrial and survival-apoptosis genes: implications for malignant melanoma therapy," Molecular Cancer Therapeutics, vol. 8, no. 5, pp. 1292-1304, 2009.

[59] A. Prigione, B. Fauler, R. Lurz, H. Lehrach, and J. Adjaye, "The senescence-related mitochondrial/oxidative stress pathway is repressed in human induced pluripotent stem cells," Stem Cells, vol. 28, no. 4, pp. 721-733, 2010.

[60] L. R. Todd, R. Gomathinayagam, and U. Sankar, "A novel Gfer-Drp1 link in preserving mitochondrial dynamics and function in pluripotent stem cells," Autophagy, vol. 6, no. 6, pp. 821-822, 2010.

[61] E. A. Schon and S. Przedborski, "Mitochondria: the next (neurode) generation," Neuron, vol. 70, no. 6, pp. 1033-1053, 2011.

[62] P. Verstreken, C. V. Ly, K. J. T. Venken, T. W. Koh, Y. Zhou, and H. J. Bellen, "Synaptic mitochondria are critical for mobilization of reserve pool vesicles at Drosophila neuromuscular junctions," Neuron, vol. 47, no. 3, pp. 365-378, 2005.

[63] P. J. Hollenbeck and W. M. Saxton, "The axonal transport of mitochondria," Journal of Cell Science, vol. 118, no. 23, pp. 5411-5419, 2005.

[64] G. B. Stokin, C. Lillo, T. L. Falzone et al., "Axonopathy and transport deficits early in the pathogenesis of Alzheimer's diseases," Science, vol. 307, no. 5713, pp. 1282-1288, 2005.

[65] K. J. De vos, A. L. Chapman, M. E. Tennant et al., "Familial amyotrophic lateral sclerosis-linked SOD1 mutants perturb fast axonal transport to reduce axonal mitochondria content," Human Molecular Genetics, vol. 16, no. 22, pp. 2720-2728, 2007.

[66] P. Shi, A. L. Ström, J. Gal, and H. Zhu, "Effects of ALS-related SOD1 mutants on dynein- and KIF5-mediated retrograde and anterograde axonal transport," Biochimica et Biophysica Acta, vol. 1802, no. 9, pp. 707-716, 2010.

[67] S. Millecamps, B. J. Gentil, F. Gros-Louis, G. Rouleau, and J. P. Julien, "Alsin is partially associated with centrosome in human cells," Biochimica et Biophysica Acta, vol. 1745, no. 1, pp. 84-100, 2005.

[68] X. Shan, P. M. Chiang, D. L. Price, and P. C. Wong, "Altered distributions of Gemini of coiled bodies and mitochondria in motor neurons of TDP-43 transgenic mice," Proceedings of the National Academy of Sciences of the United States of America, vol. 107, no. 37, pp. 16325-16330, 2010.

[69] X. Wang, B. Su, L. Zheng, G. Perry, M. A. Smith, and $\mathrm{X}$. Zhu, "The role of abnormal mitochondrial dynamics in the pathogenesis of Alzheimer's disease," Journal of Neurochemistry, vol. 109, no. 1, pp. 153-159, 2009.

[70] X. Wang, B. Su, H. G. Lee et al., "Impaired balance of mitochondrial fission and fusion in Alzheimer's disease," Journal of Neuroscience, vol. 29, no. 28, pp. 9090-9103, 2009.

[71] D. T. W. Chang, G. L. Rintoul, S. Pandipati, and I. J. Reynolds, "Mutant huntingtin aggregates impair mitochondrial 
movement and trafficking in cortical neurons," Neurobiology of Disease, vol. 22, no. 2, pp. 388-400, 2006.

[72] E. Trushina, R. B. Dyer, J. D. Badger et al., "Mutant huntingtin impairs axonal trafficking in mammalian neurons in vivo and in vitro," Molecular and Cellular Biology, vol. 24, no. 18, pp. 8195-8209, 2004.

[73] A. Weihofen, K. J. Thomas, B. L. Ostaszewski, M. R. Cookson, and D. J. Selkoe, "Pink1 forms a multiprotein complex with miro and milton, linking Pink1 function to mitochondrial trafficking," Biochemistry, vol. 48, no. 9, pp. 2045-2052, 2009.

[74] H. J. Lee, F. Khoshaghideh, S. Lee, and S. J. Lee, "Impairment of microtubule-dependent trafficking by overexpression of $\alpha$-synuclein," European Journal of Neuroscience, vol. 24, no. 11, pp. 3153-3162, 2006.

[75] F. Gillardon, "Leucine-rich repeat kinase 2 phosphorylates brain tubulin-beta isoforms and modulates microtubule stability-A point of convergence in Parkinsonian neurodegeneration?" Journal of Neurochemistry, vol. 110, no. 5, pp. 1514-1522, 2009.

[76] F. Yang, Q. Jiang, J. Zhao, Y. Ren, M. D. Sutton, and J. Feng, "Parkin stabilizes microtubules through strong binding mediated by three independent domains," The Journal of Biological Chemistry, vol. 280, no. 17, pp. 17154-17162, 2005.

[77] K. J. Kopeikina, G. A. Carlson, R. Pitstick et al., "Tau accumulation causes mitochondrial distribution deficits in neurons in a mouse model of tauopathy and in human Alzheimer's disease brain," American Journal of Pathology, vol. 179, no. 4, pp. 2071-2082, 2011.

[78] C. X. Gong and K. Iqbal, "Hyperphosphorylation of microtubule-associated protein tau: a promising therapeutic target for Alzheimer disease," Current Medicinal Chemistry, vol. 15, no. 23, pp. 2321-2328, 2008.

[79] X. Qi, M. H. Disatnik, N. Shen, R. A. Sobel, and D. MochlyRosen, "Aberrant mitochondrial fission in neurons induced by protein kinase $\mathrm{C} \delta$ under oxidative stress conditions in vivo," Molecular Biology of the Cell, vol. 22, no. 2, pp. 256-265, 2011.

[80] S. J. Tabrizi, M. W. J. Cleeter, J. Xuereb, J.-W. Taanman, J. M. Cooper, and A. H. V. Schapira, "Biochemical abnormalities and excitotoxicity in Huntington's disease brain," Annals of Neurology, vol. 45, no. 1, pp. 25-32, 1999.

[81] E. Brouillet, C. Jacquard, N. Bizat, and D. Blum, "3Nitropropionic acid: a mitochondrial toxin to uncover physiopathological mechanisms underlying striatal degeneration in Huntington's disease," Journal of Neurochemistry, vol. 95, no. 6, pp. 1521-1540, 2005.

[82] W. Song, J. Chen, A. Petrilli et al., "Mutant huntingtin binds the mitochondrial fission GTPase dynamin-related protein-1 and increases its enzymatic activity," Nature Medicine, vol. 17, no. 3, pp. 377-383, 2011.

[83] A. Kathrin Lutz, N. Exner, M. E. Fett et al., "Loss of parkin or PINK1 function increases Drp1-dependent mitochondrial fragmentation," The Journal of Biological Chemistry, vol. 284, no. 34, pp. 22938-22951, 2009.

[84] A. Sandebring, K. J. Thomas, A. Beilina et al., "Mitochondrial alterations in PINK1 deficient cells are influenced by calcineurin-dependent dephosphorylation of dynaminrelated protein 1," PLoS ONE, vol. 4, no. 5, Article ID e5701, 2009.

[85] R. K. Dagda, A. M. Gusdon, I. Pien et al., "Mitochondrially localized PKA reverses mitochondrial pathology and dysfunction in a cellular model of Parkinson's disease," Cell Death and Differentiation, 2011.

[86] V. S. Van Laar, B. Arnold, S. J. Cassady, C. T. Chu, E. A. Burton, and S. B. Berman, "Bioenergetics of neurons inhibit the translocation response of Parkin following rapid mitochondrial depolarization," Human Molecular Genetics, vol. 20, no. 5, Article ID ddq531, pp. 927-940, 2011.

[87] J. D. Rothstein, "Current hypotheses for the underlying biology of amyotrophic lateral sclerosis," Annals of Neurology, vol. 65, no. 1, pp. S3-S9, 2009.

[88] A. K. Afifi, F. P. Aleu, J. Goodgold, and B. MacKay, "Ultrastructure of atrophic muscle in amyotrophic lateral sclerosis," Neurology, vol. 16, no. 5, pp. 475-481, 1966.

[89] S. Sasaki and M. Iwata, "Dendritic synapses of anterior horn neurons in amyotrophic lateral sclerosis: an ultrastructural study," Acta Neuropathologica, vol. 91, no. 3, pp. 278-283, 1996.

[90] P. C. Wong, C. A. Pardo, D. R. Borchelt et al., "An adverse property of a familial ALS-linked SOD1 mutation causes motor neuron disease characterized by vacuolar degeneration of mitochondria," Neuron, vol. 14, no. 6, pp. 1105-1116, 1995.

[91] C. M. J. Higgins, C. Jung, and Z. Xu, "ALS-associated mutant SODIG93A causes mitochondrial vacuolation by expansion of the intermembrane space by involvement of SODI aggregation and peroxisomes," BMC Neuroscience, vol. 4, article 16, 2003.

[92] A. Raimondi, A. Mangolini, M. Rizzardini et al., "Cell culture models to investigate the selective vulnerability of motoneuronal mitochondria to familial ALS-linked G93ASOD1," European Journal of Neuroscience, vol. 24, no. 2, pp. 387-399, 2006.

[93] J. Magrané, M. A. Sahawneh, S. Przedborski et al., "Mitochondrial dynamics and bioenergetics dysfuction is associated with synaptic alterations in mutant SOD motor neurons," The Journal of Neuroscience, vol. 32, no. 1, pp. 229-242, 2012.

[94] C. Delettre, G. Lenaers, J. M. Griffoin et al., "Nuclear gene OPA1, encoding a mitochondrial dynamin-related protein, is mutated in dominant optic atrophy," Nature Genetics, vol. 26, no. 2, pp. 207-210, 2000.

[95] M. Ferré, D. Bonneau, D. Milea et al., "Molecular screening of 980 cases of suspected hereditary optic neuropathy with a report on 77 novel OPA1 mutations," Human Mutation, vol. 30, no. 7, pp. E692-E705, 2009.

[96] V. I. Mayorov, A. J. Lowrey, V. Biousse, N. J. Newman, S. D. Cline, and M. D. Brown, "Mitochondrial oxidative phosphorylation in autosomal dominant optic atrophy," BMC Biochemistry, vol. 9, no. 1, article 22, 2008.

[97] M. Spinazzi, S. Cazzola, M. Bortolozzi et al., "A novel deletion in the GTPase domain of OPA1 causes defects in mitochondrial morphology and distribution, but not in function," Human Molecular Genetics, vol. 17, no. 21, pp. 3291-3302, 2008.

[98] A. Olichon, L. Baricault, N. Gas et al., "Loss of OPA1 perturbates the mitochondrial inner membrane structure and integrity, leading to cytochrome c release and apoptosis," The Journal of Biological Chemistry, vol. 278, no. 10, pp. 7743-7746, 2003.

[99] S. Züchner, I. V. Mersiyanova, M. Muglia et al., "Mutations in the mitochondrial GTPase mitofusin 2 cause CharcotMarie-Tooth neuropathy type 2A," Nature Genetics, vol. 36, no. 5, pp. 449-451, 2004. 
[100] A. Niemann, M. Ruegg, V. La Padula, A. Schenone, and U. Suter, "Ganglioside-induced differentiation associated protein 1 is a regulator of the mitochondrial network: new implications for Charcot-Marie-Tooth disease," Journal of Cell Biology, vol. 170, no. 7, pp. 1067-1078, 2005.

[101] S. E. Rice and V. I. Gelfand, "Paradigm lost: milton connects kinesin heavy chain to miro on mitochondria," Journal of Cell Biology, vol. 173, no. 4, pp. 459-461, 2006.

[102] E. Area-Gomez, A. J. C. De Groof, I. Boldogh et al., "Presenilins are enriched in endoplasmic reticulum membranes associated with mitochondria," American Journal of Pathology, vol. 175, no. 5, pp. 1810-1816, 2009.

[103] C. Giorgi, K. Ito, H. K. Lin et al., "PML regulates apoptosis at endoplasmic reticulum by modulating calcium release," Science, vol. 330, no. 6008, pp. 1247-1251, 2010.

[104] X. Lei, S. Zhang, A. Bohrer, and S. Ramanadham, "Calciumindependent phospholipase A2 (iPLA2 $\beta$ )- mediated ceramide generation plays a key role in the cross-talk between the endoplasmic reticulum (ER) and mitochondria during ER stress-induced insulin-secreting cell apoptosis," The Journal of Biological Chemistry, vol. 283, no. 50, pp. 34819-34832, 2008.

[105] E. Ziviani, R. N. Tao, and A. J. Whitworth, "Drosophila parkin requires PINK1 for mitochondrial translocation and ubiquitinates mitofusin," Proceedings of the National Academy of Sciences of the United States of America, vol. 107, no. 11, pp. 5018-5023, 2010.

[106] A. Tanaka, M. M. Cleland, S. Xu et al., "Proteasome and p97 mediate mitophagy and degradation of mitofusins induced by Parkin," Journal of Cell Biology, vol. 191, no. 7, pp. 1367-1380, 2010.

[107] H. Wang, P. Song, L. Du et al., "Parkin ubiquitinates Drp1 for proteasome-dependent degradation: implication of dysregulated mitochondrial dynamics in Parkinson disease," The Journal of Biological Chemistry, vol. 286, no. 13, pp. 11649-11658, 2011.

[108] M. Manczak, T. S. Anekonda, E. Henson, B. S. Park, J. Quinn, and P. H. Reddy, "Mitochondria are a direct site of $\mathrm{A} \beta$ accumulation in Alzheimer's disease neurons: Implications for free radical generation and oxidative damage in disease progression," Human Molecular Genetics, vol. 15, no. 9, pp. 1437-1449, 2006.

[109] X. Wang, B. Su, H. Fujioka, and X. Zhu, "Dynamin-like protein 1 reduction underlies mitochondrial morphology and distribution abnormalities in fibroblasts from sporadic Alzheimer's disease patients," American Journal of Pathology, vol. 173, no. 2, pp. 470-482, 2008.

[110] D. H. Cho, T. Nakamura, J. Fang et al., " $\beta$-Amyloid-related mitochondrial fission and neuronal injury," Science, vol. 324, no. 5923, pp. 102-105, 2009.

[111] T. Nakamura, P. Cieplak, D. H. Cho, A. Godzik, and S. A. Lipton, "S-Nitrosylation of Drp1 links excessive mitochondrial fission to neuronal injury in neurodegeneration," Mitochondrion, vol. 10, no. 5, pp. 573-578, 2010.

[112] K. Hirai, G. Aliev, A. Nunomura et al., "Mitochondrial abnormalities in Alzheimer's disease," Journal of Neuroscience, vol. 21, no. 9, pp. 3017-3023, 2001.

[113] K. Acevedo-Torres, L. Berríos, N. Rosario et al., "Mitochondrial DNA damage is a hallmark of chemically induced and the R6/2 transgenic model of Huntington's disease," DNA Repair, vol. 8, no. 1, pp. 126-136, 2009.

[114] V. Costa, M. Giacomello, R. Hudec et al., "Mitochondrial fission and cristae disruption increase the response of cell models of Huntington's disease to apoptotic stimuli," EMBO Molecular Medicine, vol. 2, no. 12, pp. 490-503, 2010.

[115] U. P. Shirendeb, M. J. Calkins, M. Manczak et al., "Mutant Huntingtin's interaction with mitochondrial protein Drp1 impairs mitochondrial biogenesis and causes defective axonal transport and synaptic degeneration in Huntington's disease," Human Molecular Genetics, vol. 21, no. 2, Article ID ddr475, pp. 406-420, 2012.

[116] H. Wang, P. J. Lim, M. Karbowski, and M. J. Monteiro, "Effects of overexpression of Huntingtin proteins on mitochondrial integrity," Human Molecular Genetics, vol. 18, no. 4, pp. 737-752, 2009.

[117] A. Cassidy-Stone, J. E. Chipuk, E. Ingerman et al., "Chemical inhibition of the mitochondrial division dynamin reveals its role in Bax/Bak-dependent mitochondrial outer membrane permeabilization," Developmental Cell, vol. 14, no. 2, pp. 193-204, 2008.

[118] C. Brooks, Q. Wei, S. G. Cho, and Z. Dong, "Regulation of mitochondrial dynamics in acute kidney injury in cell culture and rodent models," Journal of Clinical Investigation, vol. 119, no. 5, pp. 1275-1285, 2009.

[119] S. B. Ong, S. Subrayan, S. Y. Lim, D. M. Yellon, S. M. Davidson, and D. J. Hausenloy, "Inhibiting mitochondrial fission protects the heart against ischemia/reperfusion injury," Circulation, vol. 121, no. 18, pp. 2012-2022, 2010.

[120] J. X. Wang, J. Q. Jiao, Q. Li et al., "MiR-499 regulates mitochondrial dynamics by targeting calcineurin and dynamin-related protein-1," Nature Medicine, vol. 17, no. 1, pp. 71-78, 2011.

[121] J. Park, S. B. Lee, S. Lee et al., "Mitochondrial dysfunction in Drosophila PINK1 mutants is complemented by parkin," Nature, vol. 441, no. 7097, pp. 1157-1161, 2006.

[122] Y. Yang, S. Gehrke, Y. Imai et al., "Mitochondrial pathology and muscle and dopaminergic neuron degeneration caused by inactivation of Drosophila Pink1 is rescued by Parkin," Proceedings of the National Academy of Sciences of the United States of America, vol. 103, no. 28, pp. 10793-10798, 2006.

[123] J. Blackinton, M. Lakshminarasimhan, K. J. Thomas et al., "Formation of a stabilized cysteine sulfinic acid is critical for the mitochondrial function of the parkinsonism protein DJ-1," The Journal of Biological Chemistry, vol. 284, no. 10, pp. 6476-6485, 2009.

[124] G. Krebiehl, S. Ruckerbauer, L. F. Burbulla et al., "Reduced basal autophagy and impaired mitochondrial dynamics due to loss of Parkinson's disease-associated protein DJ-1," PLoS ONE, vol. 5, no. 2, Article ID e9367, 2010.

[125] M. J. Barsoum, H. Yuan, A. A. Gerencser et al., "Nitric oxide-induced mitochondrial fission is regulated by dynamin-related GTPases in neurons," The EMBO Journal, vol. 25, no. 16, pp. 3900-3911, 2006.

[126] M. Gomez-Lazaro, N. A. Bonekamp, M. F. Galindo, J. Jordán, and M. Schrader, "6-Hydroxydopamine (6-OHDA) induces Drp1-dependent mitochondrial fragmentation in SH-SY5Y cells," Free Radical Biology and Medicine, vol. 44, no. 11, pp. 1960-1969, 2008.

[127] K. Fujita, M. Yamauchi, K. Shibayama, M. Ando, M. Honda, and Y. Nagata, "Decreased cytochrome c oxidase activity but unchanged superoxide dismutase and glutathione peroxidase activities in the spinal cords of patients with amyotrophic lateral sclerosis," Journal of Neuroscience Research, vol. 45, no. 3, pp. 276-281, 1996. 
[128] G. K. Dhaliwal and R. P. Grewal, "Mitochondrial DNA deletion mutation levels are elevated in ALS brains," NeuroReport, vol. 11, no. 11, pp. 2507-2509, 2000.

[129] R. Lodi, C. Tonon, M. L. Valentino et al., "Deficit of in vivo mitochondrial ATP production in OPA1-related dominant optic atrophy," Annals of Neurology, vol. 56, no. 5, pp. 719-723, 2004.

[130] C. Zanna, A. Ghelli, A. M. Porcelli et al., "OPA1 mutations associated with dominant optic atrophy impair oxidative phosphorylation and mitochondrial fusion," Brain, vol. 131, no. 2, pp. 352-367, 2008.

[131] D. A. Mackey, R. J. Oostra, T. Rosenberg et al., "Primary pathogenic mtDNA mutations in multigeneration pedigrees with Leber hereditary optic neuropathy," American Journal of Human Genetics, vol. 59, no. 2, pp. 481-485, 1996.

[132] S. Cipolat, T. Rudka, D. Hartmann et al., "Mitochondrial rhomboid PARL regulates cytochrome $\mathrm{c}$ release during apoptosis via OPA1-dependent cristae remodeling," Cell, vol. 126, no. 1, pp. 163-175, 2006.

[133] N. Phasukkijwatana, B. Kunhapan, J. Stankovich et al., "Genome-wide linkage scan and association study of PARL to the expression of LHON families in Thailand," Human Genetics, vol. 128, no. 1, pp. 39-49, 2010.

[134] S. H. Chung, M. Calafiore, J. M. Plane, D. E. Pleasure, and W. Deng, "Apoptosis inducing factor deficiency causes reduced mitofusion 1 expression and patterned Purkinje cell degeneration," Neurobiology of Disease, vol. 41, no. 2, pp. 445-457, 2011.

[135] J. R. Sarna and R. Hawkes, "Patterned Purkinje cell death in the cerebellum," Progress in Neurobiology, vol. 70, no. 6, pp. 473-507, 2003.

[136] H. Chen, J. M. McCaffery, and D. C. Chan, "Mitochondrial fusion protects against neurodegeneration in the cerebellum," Cell, vol. 130, no. 3, pp. 548-562, 2007.

[137] T. Ilani, D. Ben-Shachar, R. D. Strous et al., "A peripheral marker for schizophrenia: increased levels of D3 dopamine receptor mRNA in blood lymphocytes," Proceedings of the National Academy of Sciences of the United States of America, vol. 98, no. 2, pp. 625-628, 2001.

[138] M. Rosenfeld, H. Brenner-Lavie, S. G. B. Ari, A. Kavushansky, and D. Ben-Shachar, "Perturbation in mitochondrial network dynamics and in complex I dependent cellular respiration in schizophrenia," Biological Psychiatry, vol. 69, no. 10, pp. 980-988, 2011.

[139] C. Verny, D. Loiseau, C. Scherer et al., "Multiple sclerosislike disorder in OPA1-related autosomal dominant optic atrophy," Neurology, vol. 70, no. 13, pp. 1152-1153, 2008.

[140] R. Dutta, J. McDonough, X. Yin et al., "Mitochondrial dysfunction as a cause of axonal degeneration in multiple sclerosis patients," Annals of Neurology, vol. 59, no. 3, pp. 478-489, 2006.

[141] A. Makino, B. T. Scott, and W. H. Dillmann, "Mitochondrial fragmentation and superoxide anion production in coronary endothelial cells from a mouse model of type 1 diabetes," Diabetologia, vol. 53, no. 8, pp. 1783-1794, 2010.

[142] J. H. Lee, K. Hoa Nguyen, S. Mishra, and B. L. G. Nyomba, "Prohibitin is expressed in pancreatic $\beta$-cells and protects against oxidative and proapoptotic effects of ethanol," FEBS Journal, vol. 277, no. 2, pp. 488-500, 2010.

[143] T. M. Bosley, C. S. Constantinescu, C. R. Tench, and K. K. Abu-Amero, "Mitochondrial changes in leukocytes of patients with optic neuritis," Molecular Vision, vol. 13, pp. 1516-1528, 2007.

[144] L. Weiss, R. Or, R. C. Jones et al., "Preimplantation Factor (PIF*) reverses neuroinflammation while promoting neural repair in EAE model," Journal of the Neurological Sciences, vol. 312, no. 1-2, pp. 146-157, 2012.

[145] L. Weiss, S. Bernstein, R. Jones et al., "Erratum to: preimplantation factor (PIF) analog prevents type I diabetes mellitus (TIDM) development by preserving pancreatic function in NOD mice," Endocrine, vol. 40, no. 1, pp. 41-54, 2011.

[146] P. H. Krammer, R. Arnold, and I. N. Lavrik, "Life and death in peripheral T cells," Nature Reviews Immunology, vol. 7, no. 7, pp. 532-542, 2007.

[147] R. L. Contento, S. Campello, A. E. Trovato, E. Magrini, F. Anselmi, and A. Viola, "Adhesion shapes T cells for prompt and sustained T-cell receptor signalling," The EMBO Journal, vol. 29, no. 23, pp. 4035-4047, 2010.

[148] E. Abarca-Rojano, S. Muñiz-Hernández, M. M. B. MorenoAltamirano, R. Mondragón-Flores, F. Enriquez-Rincón, and F. J. Sánchez-García, "Re-organization of mitochondria at the NK cell immune synapse," Immunology Letters, vol. 122, no. 1, pp. 18-25, 2009.

[149] C. Kummerow, C. Junker, K. Kruse, H. Rieger, A. Quintana, and M. Hoth, "The immunological synapse controls local and global calcium signals in T lymphocytes," Immunological Reviews, vol. 231, no. 1, pp. 132-147, 2009.

[150] P. Matarrese, A. Tinari, E. Mormone et al., "Galectin-1 sensitizes resting human $\mathrm{T}$ lymphocytes to Fas (CD95)mediated cell death via mitochondrial hyperpolarization, budding, and fission," The Journal of Biological Chemistry, vol. 280, no. 8, pp. 6969-6985, 2005.

[151] M. Bras, V. J. Yuste, G. Roué et al., "Drp1 mediates caspaseindependent type III cell death in normal and leukemic cells," Molecular and Cellular Biology, vol. 27, no. 20, pp. 7073-7088, 2007. 

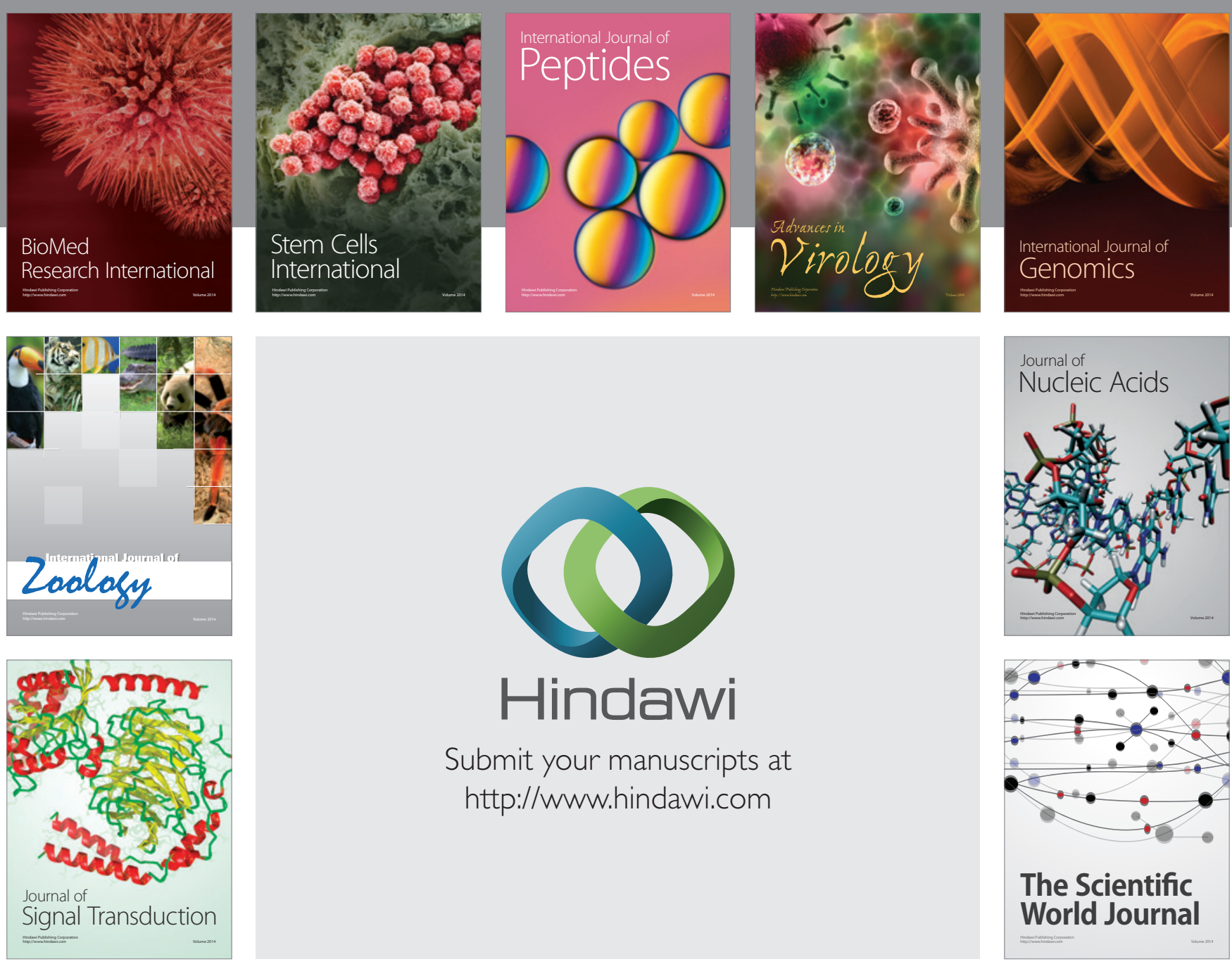

Submit your manuscripts at

http://www.hindawi.com
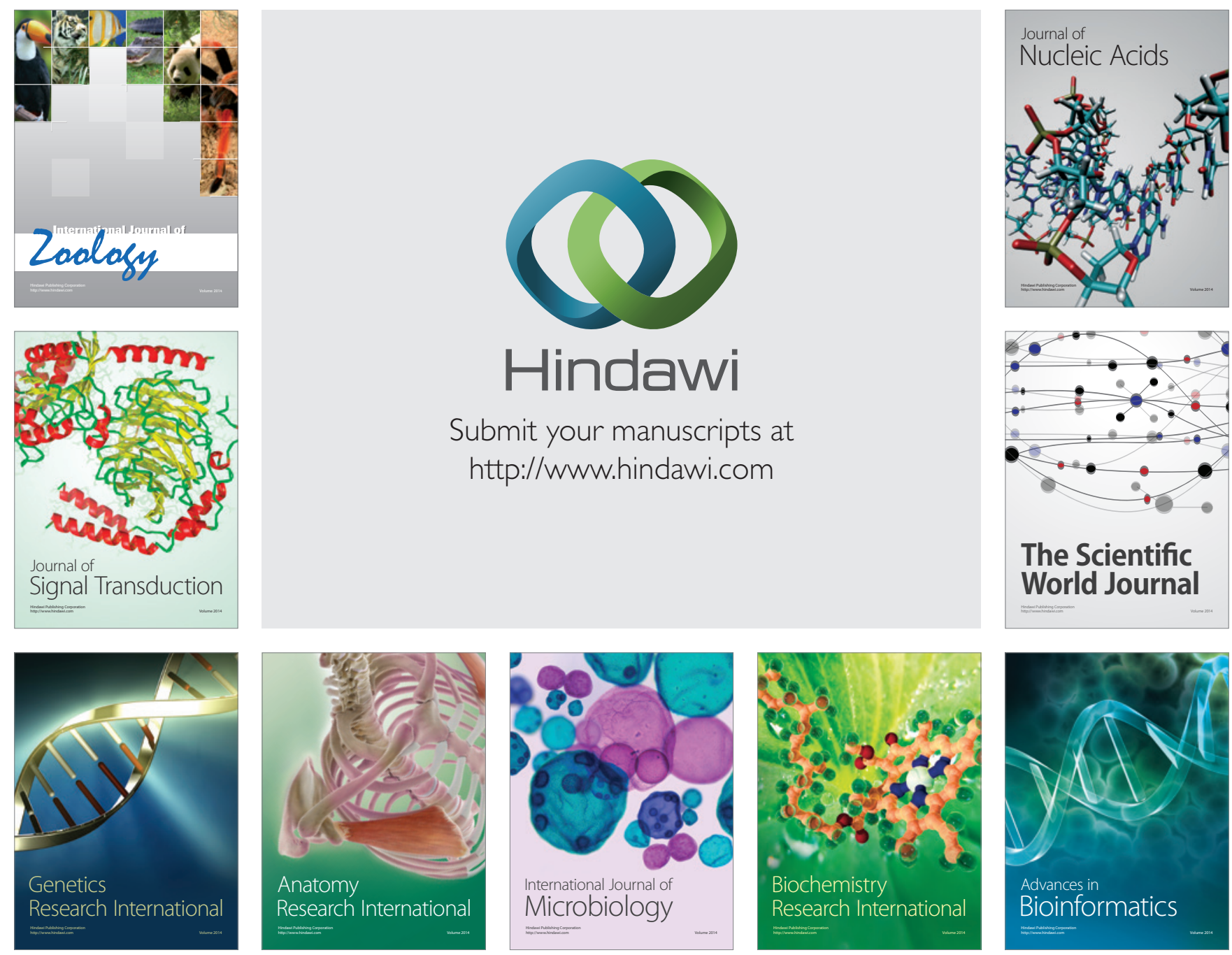

The Scientific World Journal
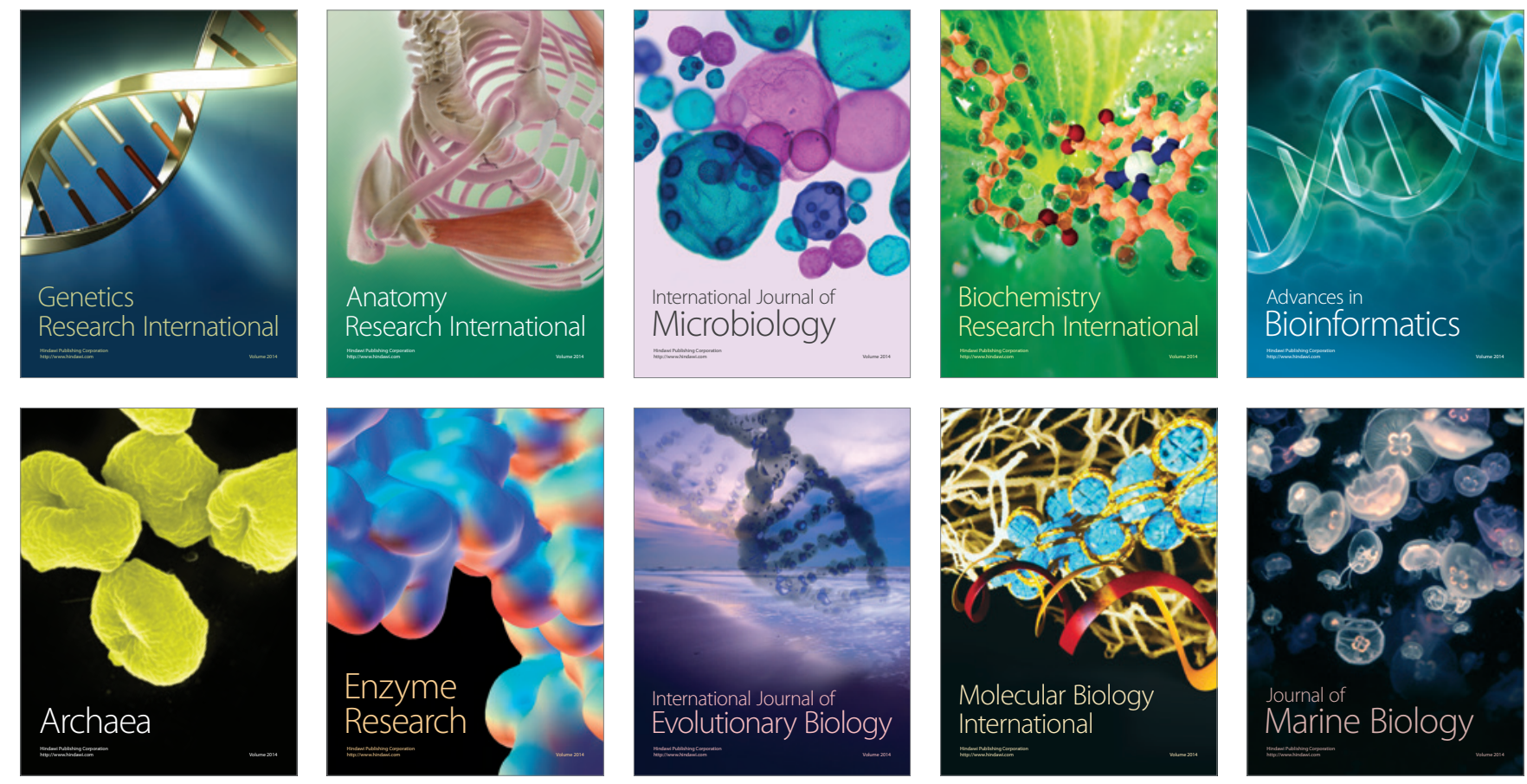